Int. J. Electrochem. Sci., 14 (2019) 9239 - 9254

International Journal of

ELECTROCHEMICAL

SCIENCE

WWW.electrochemsci.org

\title{
Investigation of the Material Removal Mechanism in Electrochemical Discharge Drilling Using a High-Speed Rotating Helical Tool-Electrode
}

\author{
Xianchun Shi, Shaofu Huang ${ }^{*}$ Long Wang \\ School of Mechanical Engineering, Anhui University of Science and Technology, 168 Taifeng Road, \\ Anhui, Huainan 232001, China. \\ *E-mail: huangshaofu1974@163.com
}

doi: $10.20964 / 2019.09 .84$

Received: 24 May 2019 / Accepted: 17 July 2019 / Published: 5 August 2019

The electrochemical discharge machining (ECDM) process is an effective way for non-traditional machining technology to machine micro-pits on conductive, non-conductive, hard and brittle materials, including glass, quartz, stainless steel and so on. In this paper, many experiments are discussed that investigate the material removal mechanism during the electrochemical discharge drilling (ECDD) process. The present research mainly discusses the effect of tool-electrode rotational speed on gas film formation, the electric discharge phenomenon, machining current, diameter of the micro-pit, machining depth of the micro-pit and material removal rate (MRR) of the work-piece. The experimental results demonstrate that when the tool-electrode is in a high-speed rotational state, removal of the work-piece material is due to the synergy of electrochemical corrosion and electric spark discharge. By contrast, when the tool-electrode is in a stationary state, the removal of the work-piece material is mainly by electrochemical corrosion. In addition, the experimental results show that the surface of the gas film becomes denser and more uniform with the increase in tool-electrode rotational speed and that the MRR is significantly increased. Eventually, a series of micro-pits are successfully fabricated by this high-speed rotating ECDD process.

Keywords: Electrochemical discharge machining (ECDM); Electrochemical discharge drilling (ECDD); Micro-pit; Tool-electrode rotational speed; the machining current, Material removal rate (MRR).

\section{FULL TEXT}

(C) 2019 The Authors. Published by ESG (www.electrochemsci.org). This article is an open access article distributed under the terms and conditions of the Creative Commons Attribution license (http://creativecommons.org/licenses/by/4.0/). 